\title{
Spectral Properties of Iron-Deficient Corn and Sunflower Leaves
}

\author{
Marco Mariotti, ${ }^{*}$ Laura Ercoli, ${ }^{\dagger}$ and Alessandro Masoni ${ }^{*}$
}

\begin{abstract}
$P_{1}$ studied, but little is known concerning the effects of iron deficiency-induced modifications in leaf spectral properties. Spectral changes in corn and sunflower plants grown in nutrient solutions containing five iron rates from $\mathrm{mg}$ $L^{-1} 0$ to $4 \mathrm{mg} \mathrm{L}^{-1}$ were therefore investigated. In both corn and sunflower, iron deficiency decreased leaf dry weight, area, iron concentration, chlorophyll a and b concentrations, and absorptance, increased reflectance and transmittance, and shifted the red edge position of reflectance curves towards shorter wavelengths. Leaf iron concentration was well correlated with leaf chlorophyll $\mathrm{a}(r=0.92)$ and $\mathrm{b}(r=0.93)$ concentrations across crop species. Reflectance was a nonlinear inverse function, and absorptance was a nonlinear increasing function of leaf iron concentration and leaf chlorophyll a concentration. Corn was more sensitive to iron deficiency than sunflower and corn required higher iron concentration than sumflower for optimal grouth. (C) Elsevier Science Inc., 1996
\end{abstract}

\section{INTRODUCTION}

Leaf spectral properties are linked to leaf morphological and physiological conditions. Nutritional effects on spectral properties have been investigated in studies on several crop plants. After the early work of Al-Abbas et al. (1974) examining reflectance, absorptance, and transmittance spectra of normal and $\mathrm{N}, \mathrm{P}, \mathrm{K}, \mathrm{S}, \mathrm{Ca}$, and $\mathrm{Mg}$ deficient corn leaves, other authors studied the effect of $\mathrm{N}$ on soybean (Chappelle et al., 1992) and corn (Ercoli et al., 1993; McMurtrey et al., 1994), and of P, As, and Se on soybean (Milton et al., 1989; 1991). Results

\footnotetext{
Dipartimento di Agronomia e Gestione dell'Agro-Fcosistema, University of Pisa, Italy

Scuola Superiore di Studi Universitari e di Perfezionamento S. Anua, Pisa, Italy

Address correspondence to A. Masoni, Dip. Agronomia e Gestione dell'Agro-Ecosistema, via S. Michele degli Scalzi, 2, 56100 Pisa, Italy.

Received 17 Octoher 1995; revised 23 Warch 1996.
}

indicate that nutritional deficiency usually decreases absorptance and increases reflectance and transmittance in the visible wavelengths. An index proposed for evaluating the changes in spectral properties is the red edge, the point of maximum slope in leaf reflectance spectra that occurs between the wavelengths of approximately 680-740 nm (Curran et al., 1991). Horler et al. (1983) summarized knowledge concerning variation in shape and position of the red edge, and showed that the red edge shift depends on chlorophyll content.

Iron is an essential element for plants, and agricultural production is lowered whenever it is deficient. Plant response to iron deficiency has been recently reviewed by Abadia (1992). Iron deficiency decreases the amount of green pigments in plants, and, consequently, reduces photosynthetic rate and dry matter accumulation. However, the effects of iron deficiency on leaf spectral properties of plants is poorly known.

The purpose of this article is, therefore, to document the changes in leaf spectral properties that occurred in corn and sunflower plants dosed with five rates of iron.

\section{MATERIALS AND METHODS}

Research was carried out in the greenhouse during 1993 at the Department of Agronomia e Gestione dell'AgroEcosistema, University of Pisa, Italy.

Seeds of hybrid Laurus corn (Zea Mays L.) and hybrid Oleica sunflower (Helianthus annuus L.) were sown in plastic pots of $6 \mathrm{~cm}$ height and diameter filled with agriperlite and deionized water. Date of sowing was 5 March for both species. Three seeds were sown in each pot. Ten days after germination, seedlings were thinned to one per pot, and the pots were placed in plastic trays containing nutrient solution. For each species and iron treatment 90 pots were used. Five concentrations of the iron were applied: $4 \mathrm{mg} \mathrm{L}^{-1}$, which we assumed to be the optimal rate for corn and sunflower growth in the experimental condition, $3 \mathrm{mg} \mathrm{L}^{-1}$ (75\% of optimum), 
designated as moderate deficiency, $2 \mathrm{mg} \mathrm{L}^{-1}$ and $1 \mathrm{mg}$ $\mathrm{L}^{-1}$ (50\% and $25 \%$ of optimum), both designated as strong deficiency, and $0 \mathrm{mg} \mathrm{L}^{-1}$, designated as complete deficiency. Iron was added to the nutrient solution as ferric ethylenediamine tetraacetic acid (Fe-EDTA). The basic composition of the nutrient solution was, following Clark (1982) (in $\mathrm{mg} \mathrm{L}^{-1}$ ): $\mathrm{NO}_{3}-\mathrm{N}, 321 ; \mathrm{Ca}, 302 ; \mathrm{K}, 283$; $\mathrm{Cl}, 65 ; \mathrm{S}, 58.5 ; \mathrm{NH}_{4}-\mathrm{N}, 39 ; \mathrm{Mg}, 37.8 ; \mathrm{Na}, 4.56 ; \mathrm{P}, 2 ; \mathrm{Mn}$, $0.974 ; \mathrm{B}, 0.536 ; \mathrm{Zn}, 0.3 ; \mathrm{Cu}, 0.076 ; \mathrm{Mo}, 0.155$. The growth solution was changed every 3 days and $\mathrm{pH}$ was adjusted daily to 6.5 with $\mathrm{HNO}_{3}$ or $\mathrm{NaOH}$. Deionized water was used throughout the experiment and added as needed to maintain solution volume.

Measurements were performed on the youngest fully expanded leaf and were executed when severe deficiency symptoms were clearly manifested on one group of plants. The degree of chlorosis of the measured leaf was visually rated as follows: none, slight (10-30\% interveinal chlorosis), moderate (30-100\% interveinal chlorosis and veins green), and severe (entire leaf chlorotic). Severe Fe deficiency symptoms were manifested

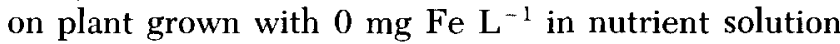
at 29 days after emergence for corn and at 45 days after emergence for sunflower. Therefore, on all plants, measurements were performed 29 days after emergence for corn and 45 days after emergence for sunflower. In both species, iron deficiency symptoms occurred in early growth stages, that is, four leaves for corn [stage 1 of the Hanway scale (Hanway, 1963)] and eleven leaves for sunflower [stage V11 of the Schneiter and Miller scale (Schneiter and Miller, 1981)]. In corn we measured the third leaf and in sunflower the eighth, which at these stages, were the highest fully expanded leaves.

Reflectance $(R)$ and transmittance $(T)$ spectra of adaxial (upper) surfaces of attached leaves were measured using a LI-COR Model LI-1800 hand-held spectroradiometer (LI-COR Inc., Lincoln, Nebraska, USA), connected to an external integrating sphere by means of a quartz fiber optic probe. Measurements were performed over the wavelength range from $400 \mathrm{~nm}$ to $1100 \mathrm{~nm}$. The scanning interval was $1 \mathrm{~nm}$. The integrating sphere included a 10-W glass halogen lamp as radiation source and a pressed barium sulphate $\left(\mathrm{BaSO}_{4}\right)$ reference standard. For both species, measurements were taken from the same surface measuring roughly $1.8 \mathrm{~cm}^{2}$ (sensor area) situated at the center of the right-hand leaf lamina. Absorptance $(A)$ was computed as $A=100-(R+T)$.

First derivatives of the $R, A$, and $T$ individual spectral curves between $678 \mathrm{~nm}$ and $740 \mathrm{~nm}$ were computed at $1-\mathrm{nm}$ intervals, and the inflection points (maxima on the first derivative spectra) of the red edge were used to define the position of the edge. The derivative spectra for $R, A$, and $T$ were calculated by fitting a third-order polynomial into the measured data with the least squares method, as suggested by Savitzky and Golay (1964).

Immediately following spectroradiometric measurements, area and fresh weight of the measured leaves were determined. Leaf area was determined with an image analyzer (Leica Quantimet 500). Dry weight divided by area of the sampled leaves gave specific leaf weight (SLW). Ten $50-\mathrm{mm}^{2}$-area disk samples were then collected from each leaf for chlorophyll determination. Disks were placed in a test tube, stoppered, frozen with dry ice for transport to the laboratory, and then stored at $-18^{\circ} \mathrm{C}$ until chlorophyll analysis. Absorptance of $\mathrm{N}, \mathrm{N}$-dimethylformamide leaf sample extract was measured at $664 \mathrm{~nm}$ and $647 \mathrm{~nm}$ on a spectrophotometer (Lambda 6 UV/VIS, Perkin-Elmer) using 10-mm path length cuvettes. Chlorophyll $a$ and $b$, expressed in moles on leaf area basis, were determined according to the Moran (1982) formulae. The remaining portion of the leaf was used for moisture determination (dried to constant weight at $75^{\circ} \mathrm{C}$ ). Owing to the low size of leaves, samples for iron analysis consisted of 20 leaves, taken from 20 plants (one leaf per plant), grown the same as those utilized for spectroradiometric measurements. In accordance with Ohki (1984), samples were ground to pass a 40 -mesh stainless steel screen. Samples $(0.5 \mathrm{~g})$ were wet-ashed by overnight predigestion in 14-ml concentrated $\mathrm{HNO}_{3}-\mathrm{HClO}_{4}$ mixture $(5: 2 \mathrm{v} / \mathrm{v}$ basis $)$ and digestion was completed in an aluminium block heater $\left(205^{\circ} \mathrm{C}\right)$. Ashed extracts were brought to 25 -ml volume and iron was determined by atomic absorption spectrometry (Zeiss FMD3 spectrophotometer).

Since in both species deficiency symptoms were detected at different stages and on leaves of different nodal position, analysis of variance was performed separately for each species. The experimental design was a randomized complete block with five iron rates $(0 \mathrm{mg}$ $\mathrm{L}^{-1}, 1 \mathrm{mg} \mathrm{L}^{-1}, 2 \mathrm{mg} \mathrm{L}^{-1}, 3 \mathrm{mg} \mathrm{L}^{-1}$, and $4 \mathrm{mg} \mathrm{L}^{-1}$ ) and three replications. Statistical separation of means was determined using a least significant difference test (Steel and Torrie, 1981).

Correlation analyses were run between leaf iron and chlorophyll $a$ and $b$ concentrations, and between leaf chlorophyll $a$ and $b$ concentrations and mean $R, A$, and $T$ values of $10-\mathrm{nm}$ bandwidth centered on wavelengths of $429 \mathrm{~nm}, 555 \mathrm{~nm}$, and $678 \mathrm{~nm}$, and the red edge position.

\section{RESULTS AND DISCUSSION}

\section{Leaf Dry Weight, Area, and Specific Leaf Weight}

No visible iron deficiency symptoms were observed on leaves of either species at $4 \mathrm{mg} \mathrm{Fe} \mathrm{L^{-1 }}$ in the nutrient solution (normal plant). In corn, deficiency symptoms were severe at $0 \mathrm{mg} \mathrm{Fe} \mathrm{L}^{-1}, 1 \mathrm{mg} \mathrm{Fe} \mathrm{L}^{-1}$, and $2 \mathrm{mg}$ $\mathrm{Fe} \mathrm{L}^{-1}(0 \%, 25 \%$, and $50 \%$ of optimum), and moderate at $3 \mathrm{mg} \mathrm{L}^{-1}$. In sunflower symptoms were severe at 0 $\mathrm{mg} \mathrm{L}{ }^{-1}$, moderate at $1 \mathrm{mg} \mathrm{L}^{-1}$, and slight at $2 \mathrm{mg} \mathrm{Fe}$

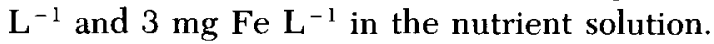

Reduction of iron in the nutrient solution led to pronounced decreases in dry weight, area, and SLW of 
Table 1. Effect of Iron Availability on Dry Weight, Area, and SLW of Corn and Sunflower Leaves

\begin{tabular}{cccc}
\hline $\begin{array}{c}\text { Fe Rate } \\
\left(m g L^{-1}\right)\end{array}$ & $\begin{array}{c}\text { Dry Weight } \\
(\text { mg per leaf })\end{array}$ & $\begin{array}{c}\text { Area } \\
\left(\mathrm{cm}^{2} \text { per leaf }\right)\end{array}$ & $\begin{array}{c}\text { SLW } \\
\left(\mathrm{mg} \mathrm{cm}^{-2}\right)\end{array}$ \\
\hline \multicolumn{4}{c}{ Corn } \\
0 & $59.2 \mathrm{a}$ & $33.4 \mathrm{a}$ & $1.8 \mathrm{a}$ \\
1 & $53,8 \mathrm{a}$ & $32.4 \mathrm{a}$ & $1.7 \mathrm{a}$ \\
2 & $56.7 \mathrm{a}$ & $36.6 \mathrm{a}$ & $1.5 \mathrm{a}$ \\
3 & $60.8 \mathrm{a}$ & $34.1 \mathrm{a}$ & $1.8 \mathrm{a}$ \\
4 & $158.7 \mathrm{~b}$ & $60.0 \mathrm{~b}$ & $2.6 \mathrm{~b}$ \\
\multicolumn{4}{c}{} \\
0 & $197.3 \mathrm{a}$ & $75.2 \mathrm{a}$ & $2.5 \mathrm{a}$ \\
1 & $214.7 \mathrm{ab}$ & $69.2 \mathrm{a}$ & $2.7 \mathrm{a}$ \\
2 & $224.7 \mathrm{ab}$ & $65.5 \mathrm{a}$ & $3.4 \mathrm{~b}$ \\
3 & $254.1 \mathrm{~b}$ & $72.0 \mathrm{a}$ & $3.5 \mathrm{~b}$ \\
4 & $385.4 \mathrm{c}$ & $88.1 \mathrm{~b}$ & $4.4 \mathrm{c}$ \\
\hline
\end{tabular}

For each species, values followed by the same letter are not significantly different at the 0.05 probability level by the LSD test.

the measured leaf of both species (Table 1). In corn, leaf dry weight, area, and SLW decreased abruptly between normal and moderately $\mathrm{Fe}$-deficient plants, while no changes occurred between moderately, strongly, and completely Fe-deficient plants. In sunflower the leaf area decrease was similar to that in corn, while dry weight and SLW decreased progressively with decreasing iron supply until strong deficiency was reached.

\section{Leaf Iron Concentration}

In corn, strong iron deficiency reduced leaf $\mathrm{Fe}$ concentration to approximately $38 \%$ of normal plant concentration, while complete deficiency induced no further change (Table 2). In sunflower, moderate iron deficiency reduced leaf $\mathrm{Fe}$ concentration to $63 \%$ and complete deficiency to $30 \%$ of normal plant concentration. In
Table 2. Effect of Iron Availability on Iron and Chlorophyll $a, b, a+b$ Concentration and Chlorophyll $a / b$ Ratio of Corn and Sunflower Leaves

\begin{tabular}{|c|c|c|c|c|c|}
\hline \multirow{3}{*}{$\begin{array}{l}\text { Fe Rate } \\
\left(m g L^{-1}\right)\end{array}$} & \multicolumn{4}{|c|}{ Leaf Concentration } & \multirow{3}{*}{$\begin{array}{c}\text { Chl } a / b \\
\text { Ratio }\end{array}$} \\
\hline & $\mathrm{Fe}$ & Chl $a$ & Chl b & Chl $a+b$ & \\
\hline & \multicolumn{4}{|c|}{$\left(\mu \mathrm{mol} m^{-2}\right)$} & \\
\hline \multicolumn{6}{|c|}{ Corn } \\
\hline 0 & $31.3 \mathrm{a}$ & $28.1 \mathrm{a}$ & $38.3 \mathrm{a}$ & $66.4 \mathrm{a}$ & $0.7 \mathrm{a}$ \\
\hline 1 & $31.9 \mathrm{a}$ & $46.0 \mathrm{~b}$ & $42.9 \mathrm{a}$ & $88.9 \mathrm{~b}$ & $1.1 \mathrm{~b}$ \\
\hline 2 & $30.3 \mathrm{a}$ & $74.4 \mathrm{c}$ & $51.7 \mathrm{~b}$ & $126.1 \mathrm{c}$ & $1.4 \mathrm{c}$ \\
\hline 3 & $46.9 \mathrm{~b}$ & $101.6 \mathrm{~d}$ & $57.5 \mathrm{~b}$ & $159.1 \mathrm{~d}$ & $1.8 \mathrm{~d}$ \\
\hline 4 & $79.8 \mathrm{c}$ & $258.6 \mathrm{e}$ & $91.5 \mathrm{c}$ & $350.1 \mathrm{e}$ & $2.8 \mathrm{e}$ \\
\hline \multicolumn{6}{|c|}{ Sunflower } \\
\hline 0 & $54.7 \mathrm{a}$ & $56.2 \mathrm{a}$ & $41.2 \mathrm{a}$ & $97.4 \mathrm{a}$ & $1.4 \mathrm{a}$ \\
\hline 1 & $102.5 \mathrm{~b}$ & $249.2 \mathrm{~b}$ & $95.8 \mathrm{~b}$ & $345.0 \mathrm{~b}$ & $2.6 \mathrm{~b}$ \\
\hline 2 & $117.7 \mathrm{~b}$ & $347.5 \mathrm{c}$ & $123.0 \mathrm{c}$ & $470.4 \mathrm{~b}$ & $2.8 \mathrm{~b}$ \\
\hline 3 & $113.1 \mathrm{~b}$ & $350.1 \mathrm{c}$ & $126.0 \mathrm{c}$ & $476.1 \mathrm{~b}$ & $2.8 \mathrm{~b}$ \\
\hline 4 & $179.5 \mathrm{c}$ & $407.5 \mathrm{~d}$ & $149.3 \mathrm{~d}$ & $556.8 \mathrm{~b}$ & $2.7 \mathrm{~b}$ \\
\hline
\end{tabular}

For each species, values followed by the same letter are not significantly different at the 0.05 probability level by the LSD test.

both species, leaf iron content in plants grown without additional iron must have derived from the seed because pure salts and deionized water were used as the nutrient solution.

Iron concentration in corn leaves was lower than that of sunflower at all iron rates. This difference decreased progressively with increasing iron deficiency and was approximately $100 \mu \mathrm{mol} \mathrm{m}{ }^{-2}$ in normal leaves and only $23 \mu \mathrm{mol} \mathrm{m}^{-2}$ in completely Fe-deficient leaves.

\section{Leaf Chlorophyll Concentration}

Iron deficiency markedly decreased leaf chlorophyll $a$ and $b$ concentration of both species. In corn, chlorophyll $a$ decreased progressively with increasing $\mathrm{Fe}$ deficiency.

Figure 1. Leaf iron concentrations relation to leaf chlorophyll $a$ and $b$ concentrations (part a) and to the chlorophyll $a / b$ ratio (part b) for corn and sunflower.
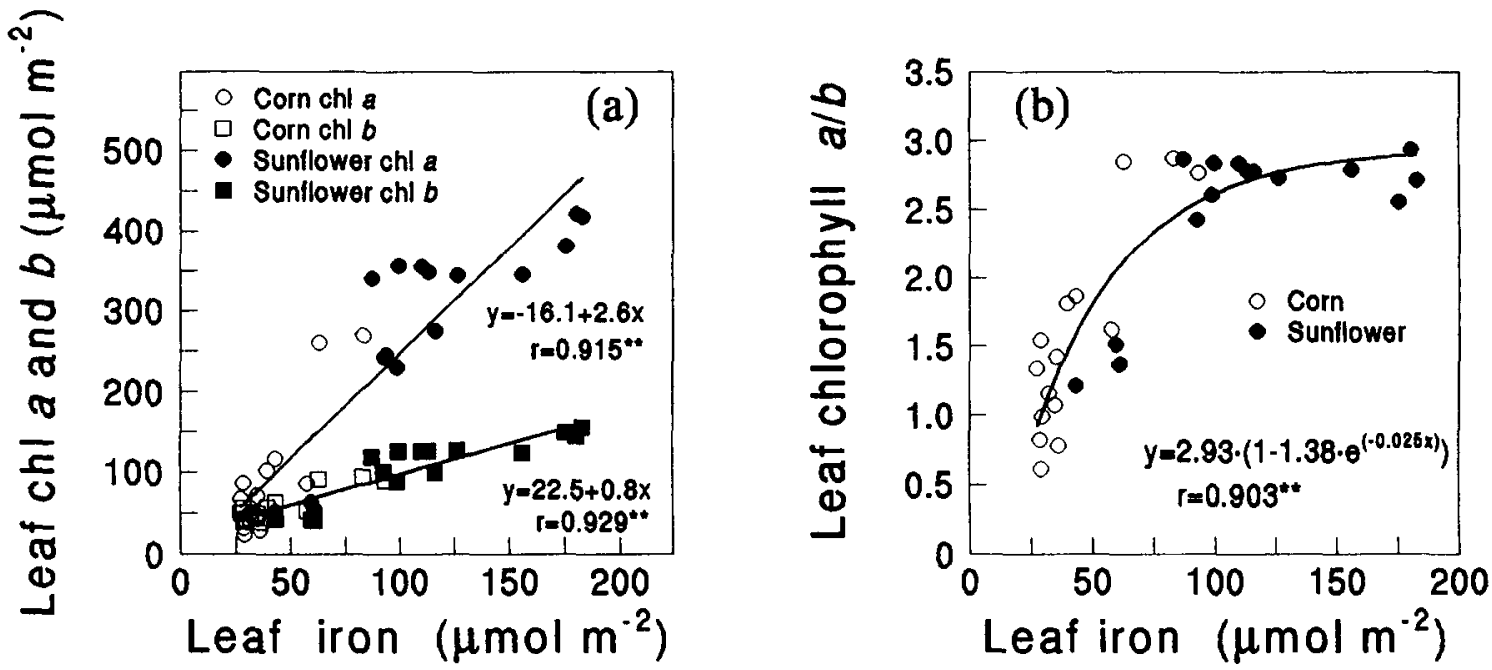
Thus in completely iron-deficient plants chlorophyll $a$ concentration was $11 \%$ of normal plant values. In sunflower grown at $3 \mathrm{mg} \mathrm{Fe} \mathrm{L}^{-1}$ and $2 \mathrm{mg} \mathrm{Fe} \mathrm{L}^{-1}$, chlorophyll $a$ concentration was about $86 \%$ of normal plants, and at $1 \mathrm{mg} \mathrm{Fe} \mathrm{L} \mathrm{L}^{-1}$ and $0 \mathrm{mg} \mathrm{Fe} \mathrm{L}^{-1}$ it was $61 \%$ and $14 \%$, respectively (Table 2 ). Corn presented lower concentration of leaf chlorophyll $a$ than sunflower at all Fe rates. Furthermore, the difference between these species was higher at $2 \mathrm{mg} \mathrm{Fe} \mathrm{L}{ }^{-1}\left(273 \mu \mathrm{mol} \mathrm{m}{ }^{-2}\right)$ than at $4 \mathrm{mg} \mathrm{Fe} \mathrm{L}^{-1}\left(149 \mu \mathrm{mol} \mathrm{m}^{-2}\right)$ or $0\left(28 \mu \mathrm{mol} \mathrm{m}^{-2}\right)$.

Iron deficiency decreased leaf chlorophyll $b$ concentration of both species similarly to chlorophyll $a$, but with a lower rate of decrease. Leaf chlorophyll $b$ concentration in completely iron deficient plants was $42 \%$ of normal plant in corn and $28 \%$ in sunflower.

A positive linear relationship was observed between leaf chlorophyll $a$ and $b$ concentration and leaf iron concentration, irrespective of species (Fig. 1). In completely iron-deficient plants chlorophyll $a$ and $b$ concentration values were similar but differences between chlorophyll $a$ and $b$ concentration increased progressively with increasing leaf $\mathrm{Fe}$ concentration, owing to a higher chlorophyll $a$ rate of increase per unit of $\mathrm{Fe}$ concentration.

Corn and sunflower were found to differ in sensitivity of the chlorophyll $a / b$ ratio to iron deficiency (Table
2). This ratio was about 2.8 in normal corn and sunflower leaves, but in corn it decreased progressively with increasing iron deficiency, reaching 0.7 in completely deficient plants, while in sunflower it did not change between normal, moderately, and strongly deficient plants, decreasing to 1.4 in completely deficient plants. The chlorophyll $a / b$ ratio was curvilinearly correlated with leaf iron concentration, irrespective of species. At concentration above $70 \mu \mathrm{mol}$ leaf $\mathrm{Fe} \mathrm{m}^{-2}$, the chlorophyll $a / b$ ratio did not change appreciably, remaining 2.7, while below this threshold the ratio increased markedly with only a very slight increase in leaf Fe concentration (Fig. 1).

\section{Leaf Spectral Properties}

Figure 2 shows reflectance, absorptance, and transmittance spectra, in the $400-700 \mathrm{~nm}$ range, of the third corn leaf and eighth sunflower leaf grown with the different iron doses. Reflectance is the spectral property utilized in remote sensing for detecting stress conditions, and absorptance represents the radiation utilized by the leaf for photosynthesis. In both species the decrease in iron availability increased reflectance and decreased absorptance. Modifications induced in the spectra by iron rates were different at the various wave-
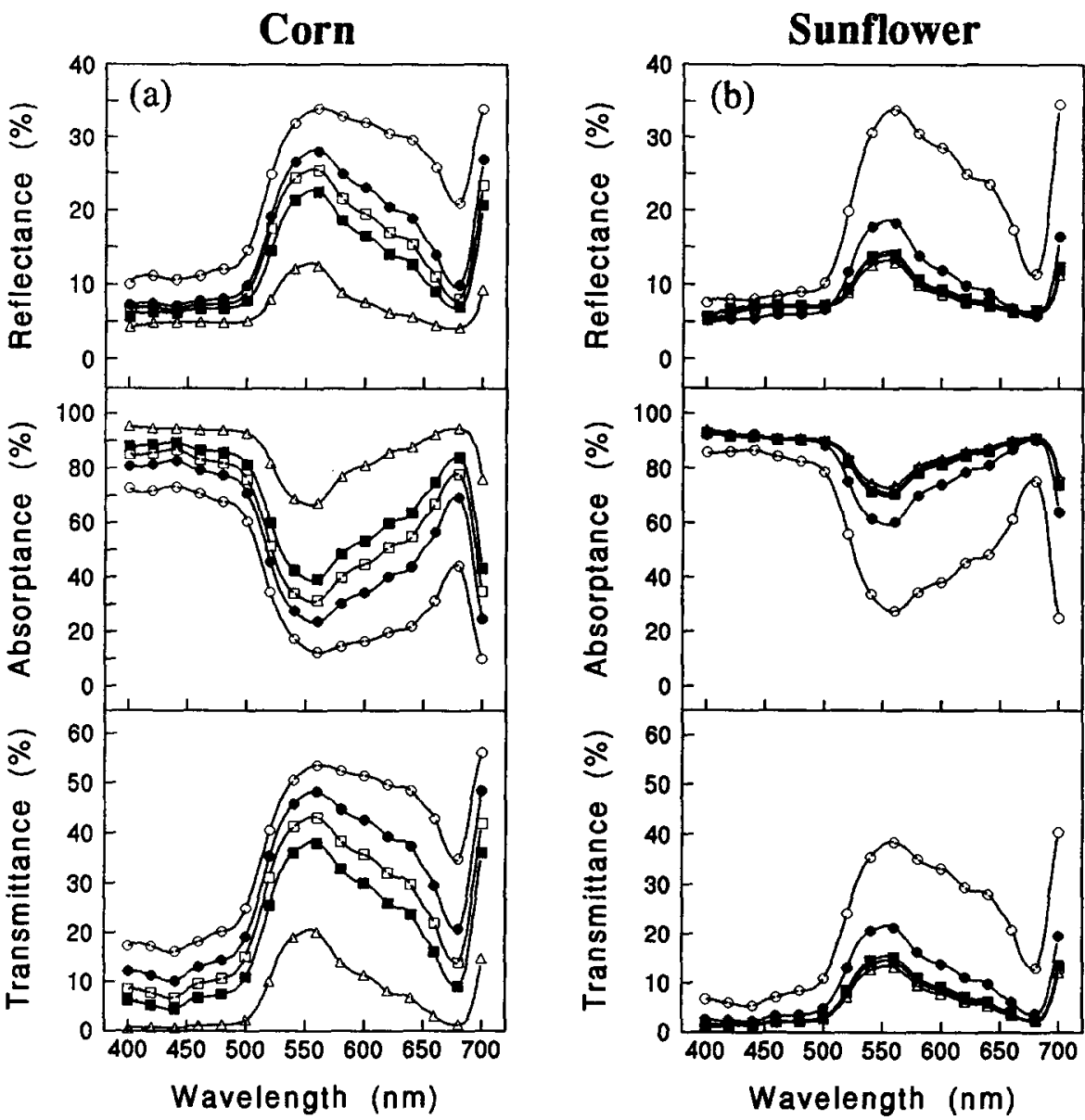

Figure 2, Measured spectra of reflectance, absorptance and transmittance of the third corn leaf and eighth sunflower leaf grown with five iron concentrations in nutrient solution. In all figures: $\mathrm{O}-\mathrm{O} 4 \mathrm{mg} \mathrm{Fe} \mathrm{L}^{-1}$; - $3 \mathrm{mg} \mathrm{Fe} \mathrm{L}^{-1} ; \square-\square 2 \mathrm{mg} \mathrm{Fe}$ $\mathrm{L}^{-1} ; \mathrm{D}-1 \mathrm{mg} \mathrm{Fe} \mathrm{L}{ }^{-1} ; \triangle-\triangle 0$ $\mathrm{mg} \mathrm{Fe} \mathrm{L}^{-1}$. 

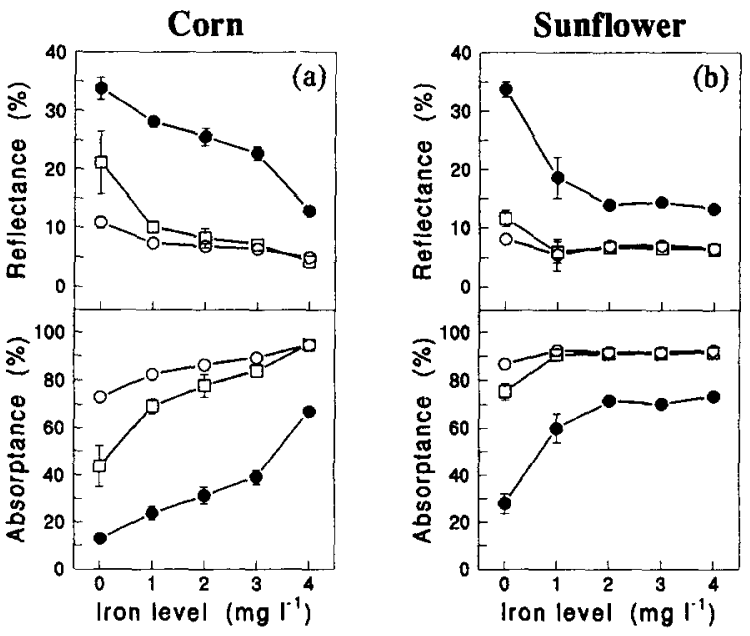

Figure 3. Effect of iron availability on reflectance and absorptance at $429 \mathrm{~nm}, 555 \mathrm{~nm}$, and $678 \mathrm{~nm}$ wavelength for corn (part a) and sunflower (part b) leaves. Values are means for $10-\mathrm{nm}$ bandwidth centered on indicated wavelengths. In all figures: $\mathrm{O}-\mathrm{O}$ $429 \mathrm{~nm},-555 \mathrm{~nm}, \square-\square 678 \mathrm{~nm}$. Vertical lines show standard deviation of the means; where not shown, the line lies within the symbol.

lengths examined. We investigated the spectral effects of iron at $429 \mathrm{~nm}, 555 \mathrm{~nm}$, and $678 \mathrm{~nm}$. These wavelengths were selected as being representative of the PAR region, since maximum in vivo chlorophyll absorption occurs at $429 \mathrm{~nm}$ and $678 \mathrm{~nm}$ and the maximum of the green reflectance peak lies at $555 \mathrm{~nm}$.

Between normal and completely iron-deficient plants, the decrease in absorptance values and the increase in reflectance were higher in corn than in sunflower at all wavelengths (Fig. 3). In both species the increase in iron rates caused the highest variations in spectral properties at $555 \mathrm{~nm}$. At $429 \mathrm{~nm}$, variations due to iron deficiency were negligible in both species.

In corn at $678 \mathrm{~nm}$, the variations of absorptance and reflectance were progressive with decreasing iron rate, and complete $\mathrm{Fe}$ deficiency reduced absorptance of normal plants by $51 \%$ and increased reflectance by $17 \%$. At $555 \mathrm{~nm}$, the variations in reflectance and absorptance were progressive with decreasing iron rate: absorptance of completely $\mathrm{Fe}$-deficient plants was $54 \%$ lower of normal plants and reflectance was $21 \%$ higher.

In sunflower at $678 \mathrm{~nm}$, no variations were observed between strongly deficient, moderately deficient, and normal plants, while complete deficiency reduced absorptance of normal plants by $16 \%$ and increased reflectance by $5 \%$. At $555 \mathrm{~nm}$, reduction of the $\mathrm{Fe}$ rate to $50 \%$ of optimum did not change reflectance and absorptance values. Further reduction to complete deficiency decreased absorptance of normal plants by $46 \%$ and increased reflectance by $21 \%$.

A curvilinear relationship between leaf iron and
Table 3. Coefficients for Equations, with Estimates of $r$, Relating Reflectance, Transmittance, and Absorptance at $429 \mathrm{~nm}, 555 \mathrm{~nm}$, and $678 \mathrm{~nm}$ to Leaf Iron Concentration and to Leaf Chlorophyll $a$ Concentration

\begin{tabular}{lrrrr}
\hline & \multicolumn{4}{c}{ Coefficients } \\
\cline { 2 - 4 } Parameter & \multicolumn{5}{c}{$a^{\dagger}$} & \multicolumn{1}{c}{$k$} & $r$ \\
\hline \multicolumn{5}{c}{ Leaf Iron Concentration } \\
$\mathrm{R}$ at 429 & 6.50 & 1.30 & 0.055 & $0.457^{*}$ \\
$\mathrm{~A}$ at 429 & 92.52 & -0.51 & 0.046 & $0.782^{* *}$ \\
$\mathrm{~T}$ at 429 & 1.21 & 31.43 & 0.045 & $0.835^{* *}$ \\
$\mathrm{R}$ at 555 & 10.32 & 2.97 & 0.015 & $0.787^{* *}$ \\
$\mathrm{~A}$ at 555 & 78.87 & -1.28 & 0.019 & $0.910^{* *}$ \\
$\mathrm{~T}$ at 555 & 10.69 & 6.67 & 0.021 & $0.949^{* *}$ \\
$\mathrm{R}$ at 678 & 5.89 & 3.76 & 0.039 & $0.562^{*}$ \\
$\mathrm{~A}$ at 678 & 92.49 & -0.97 & 0.039 & $0.761^{* *}$ \\
$\mathrm{~T}$ at 678 & 1.62 & 41.94 & 0.039 & $0.826^{* *}$ \\
& Leaf Chlorophyll $a$ Concentration \\
$\mathrm{R}$ at 429 & 6.19 & 2.87 & 0.050 & $0.802^{* *}$ \\
$\mathrm{~A}$ at 429 & 92.21 & -0.45 & 0.030 & $0.949^{* *}$ \\
$\mathrm{~T}$ at 429 & 1.57 & 17.67 & 0.025 & $0.935^{* *}$ \\
$\mathrm{R}$ at 555 & 12.58 & 2.14 & 0.009 & $0.952^{* *}$ \\
$\mathrm{~A}$ at 555 & 78.93 & -0.96 & 0.006 & $0.990^{* *}$ \\
$\mathrm{~T}$ at 555 & 6.99 & 7.24 & 0.005 & $0.980^{* *}$ \\
$\mathrm{R}$ at 678 & 6.36 & 13.03 & 0.062 & $0.939^{* *}$ \\
$\mathrm{~A}$ at 678 & 90.89 & -1.29 & 0.034 & $0.975^{* *}$ \\
$\mathrm{~T}$ at 678 & 2.81 & 23.45 & 0.027 & $0.971^{* *}$ \\
\hline
\end{tabular}

${ }^{+} \mathrm{a}, \mathrm{b}$, and $\mathrm{k}$ are constants in the logistic function $y=a\left(\mathrm{I}+b e^{-k x}\right)$, where $x$ is leaf iron concentration or leaf chlorophyll $a$ concentration.

* Model significant at 0.05 probability level.

** Model significant at 0.01 probability level.

chlorophyll $a$ and $b$ concentration and absorptance, reflectance, and transmittance, at wavelengths $429 \mathrm{~nm}$, $555 \mathrm{~nm}$, and $678 \mathrm{~nm}$ was observed, irrespective of species. The model used to represent this relationship was $y=a\left[1+b e^{(-k x)}\right]$, where $x$ is leaf iron or chlorophyll concentration expressed in moles per unit area (Table 3). Correlations between spectral properties and leaf chlorophyll $a$ concentration were always excellent, while those with leaf iron and chlorophyll $b$ concentration were less satisfactory. These results confirmed that chlorophyll $a$ has a dominant influence on spectral variations in the visible region of the spectrum, and Fe deficiency induces modifications in spectral properties through modifications in leaf chlorophyll concentration. In agreement with Buschmann and Nagel (1993), the wavelength best correlated was $555 \mathrm{~nm}$ for both corn and sunflower (Fig. 4).

Iron deficiency caused the red edge position in reflectance, absorptance, and transmittance spectra of both species to vary only by $2-3 \mathrm{~nm}$. Thus the red edge position will be discussed only as regards reflectance spectra (Fig. 5). In normal com and sunflower leaves the red edge was located in the same position $(713 \mathrm{~nm})$. Iron deficiency produced a shift in red edge position to shorter wavelengths. Modifications induced by iron 


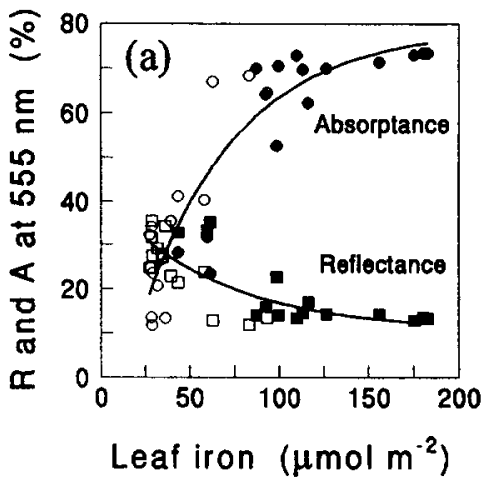

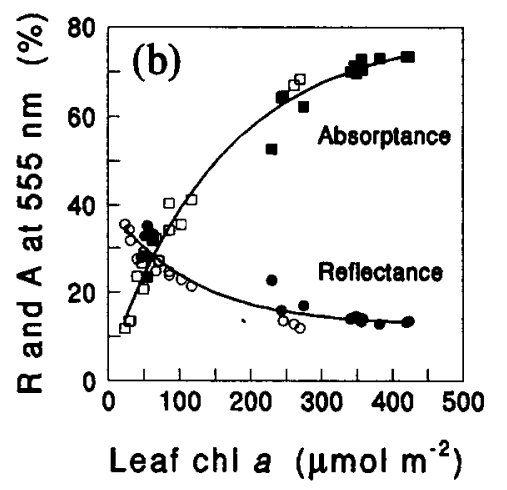

Figure 4. Leaf iron concentration (a) and leaf chlorophyll $a$ concentration (b) each versus leaf reflectance and absorptance at $555 \mathrm{~nm}$ in corn (empty markers) and sunflower (filled markers). Values are means for 10-nm bandwidth centered at $555 \mathrm{~nm}$. deficiency were different between the species. In corn the red edge shift was $7 \mathrm{~nm}$ when presence of this element in the nutrient solution increased from $0 \mathrm{mg}$ Fe $\mathrm{L}^{-1}$ to $3 \mathrm{mg} \mathrm{Fe} \mathrm{L}^{-1}$ and $15 \mathrm{~nm}$ from $3 \mathrm{mg} \mathrm{Fe} \mathrm{L}^{-1}$ to $4 \mathrm{mg} \mathrm{Fe} \mathrm{L}^{-1}$. In sunflower, red edge position shifted from $693 \mathrm{~nm}$ to $712 \mathrm{~nm}$ when Fe rate increased from $0 \mathrm{mg} \mathrm{Fe} \mathrm{L}^{-1}$ to $2 \mathrm{mg} \mathrm{Fe} \mathrm{L}^{-1}$ and the position remained

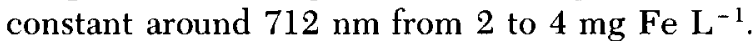

A linear relationship between red edge position and leaf chlorophyll $a$ concentration was found when corn and sunflower values were combined. An increase of $0.1 \mathrm{mmol} \mathrm{m} \mathrm{m}^{-2}$ in chlorophyll $a$ increased reflectance red-edge position by $6 \mathrm{~nm}$. This result confirmed that when one stress, such as nutrient deficiency, causes a loss of chlorophyll, red edge position shifted to shorter wavelengths.

\section{CONCLUSIONS}

Consistent with the findings of Oertli and Jacobson (1960), our findings in this study indicate that iron deficiency affects corn and sunflower similarly. In both corn and sunflower, iron deficiency decreased leaf dry weight, area, iron, and chlorophyll $a$ and $b$ concentration and absorptance, increased reflectance and transmittance, and shifted red edge position towards shorter wavelengths. In agreement with Davis et al. (1986) and Nenova and Stojanov (1993), leaf iron concentration was well correlated with leaf chlorophyll concentration, and leaf spectral properties were well correlated with leaf iron and chlorophyll concentration. The relationships were the same for both species, and values of plants grown in optimal iron conditions and in complete iron deficiency were similar between corn and sunflower. Evidently, reduction in iron availability reduced leaf iron concentration, causing reduction in leaf chlorophyll concentration and visible deficiency symptoms. The reduced leaf chlorophyll concentration, in turn, reduced absorptance and increased reflectance and transmittance. Thus leaf iron content is indirectly responsible for modifications in leaf spectral properties.

Corn and sunflower differed in their ability to utilize iron. Both species grew normally in nutrient solution with $4 \mathrm{mg} \mathrm{Fe} \mathrm{L}^{-1}$. Corn displayed moderate iron deficiency symptoms at $3 \mathrm{mg} \mathrm{Fe} \mathrm{L}^{-1}$ while sunflower dis-

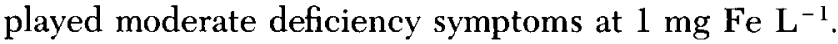
The higher concentration of iron required by corn than by sunflower is consistent with the results of Kashirad and Marschner (1974) and Römheld and Marschner (1981).

For both species the lowered iron and chlorophyll contents of iron-deficient plants resulted in decreased leaf absorptance and increased leaf reflectance.

Leaf spectral properties and leaf iron concentration are well correlated. Therefore, measurements of leaf spectral properties can be used to detect iron deficiency, provided that other possible causes of changes can be excluded. This reservation is necessary because leaf
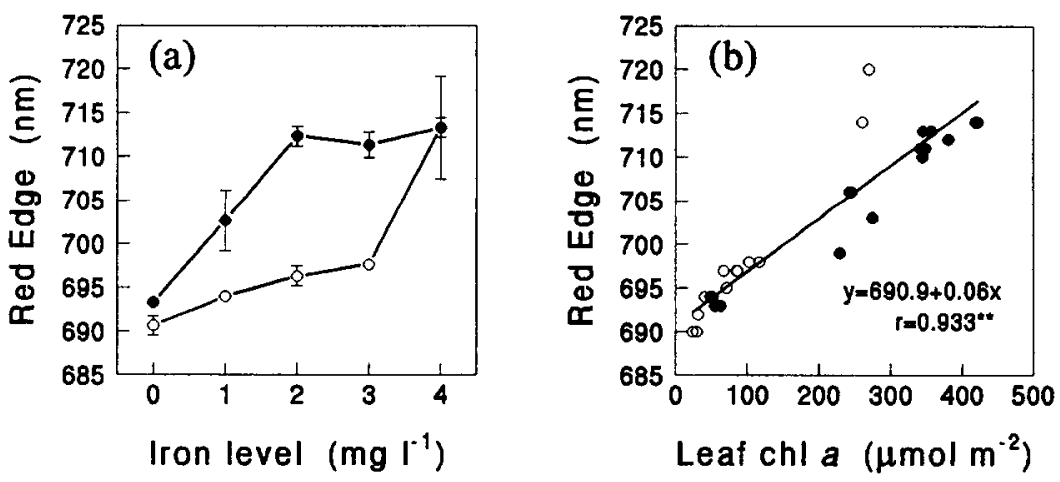

Figure 5. Reflectance red edge position for corn and sunflower leaves grown with five iron concentrations in nutrient solution (part a) and leaf chlorophyll $a$ concentration versus red edge position in reflectance and absorptance spectra (part b). Data for corn is shown by empty markers and for sunflower by filled markers. In the left figure vertical lines show standard deviation of the means; where not shown, the line lies within the symbol. 
spectral properties are not specific to iron deficiency, and similar variations have been observed when plants are subjected to other unfavorable effects, such as nitrogen stress (McMurtrey et al., 1994), water deficiency (Masoni et al., 1993), and leaf senescence (Masoni et al., 1994).

Research was supported by the National Research Council of Italy.

\section{REFERENCES}

Abadia, J (1992), Leaf response to Fe deficiency: a review. J. Plant Nutr. 15:1699-1713.

Al-Abbas, A. H., Barr, R., Hall, J. D., Crane, F. L., and Baumgardner, M. F. (1974), Spectra of normal and nutrientdeficient maize leaves. Agron. J. 66:16-20.

Buschmann, C., and Nagel, E. (1993), In vivo spectroscopy and internal optics of leaves as basis for remote sensing of vegetation. Int. J. Remote Sens. 4:711-722.

Chappelle, E. W., Kim, M. S., and McMurtrey, J. E. (1992), Ratio analysis of reflectance spectra (RARS): an algorithm for the remote estimation of the concentrations of chlorophyll $a$, chlorophyll $b$, and carotenoids in soybean leaves. Remote Sens. Environ. 39:239-247.

Clark, R. B. (1982), Nutrient solution growth of sorghum and corn in mineral nutrition studies. J. Plant Nutr. 5:10391057.

Curran, P. J., Dungan, J. L., Macler, B. A., and Plummer, S. E. (1991), The effect of a red leaf pigment on the relationship between red edge and chlorophyll concentration. Remote Sens. Environ. 35:69-76.

Davis, T. D., Jolley, V. D., Walser, R. H., Brown, J. C., and Blaylock, A. D. (1986), Net photosynthesis of Fe-efficient and $\mathrm{Fe}$-inefficient soybean cultivars grown under varying iron levels. J. Plant Nutr. 9:671-681.

Ercoli, L., Mariotti, M., Masoni, A., and Massantini, F. (1993), Relationship between nitrogen and chlorophyll content and spectral properties in corn leaves. Eur. J. Agron. 2:113117.

Hanway, J. J. (1963), Growth stages of corn (Zea mays, L.). Agron. J. 55:487-492.

Horler, D. N. H., Dockray M., and Barber, J. (1983), The red edge of plant leaf reflectance. Int. J. Remote Sens. 2:273288.
Kashirad, A., and Marschner, H. (1974), Effect of pH and phosphate on iron nutrition of sunflower and corn plants. Agrochimica 6:497-508.

Masoni, A., Massantini, F., Volterrani, M., and Mariotti, M. (1993), Effect of water stress on spectral properties of corn (Zea mays L.) and sunflower (Helianthus annuus L.) leaves. Agric. Med. 123:72-85.

Masoni, A., Ercoli, L., Mariotti, M., and Barberi, P. (1994), Changes in spectral properties of ageing and senescing maize and sunflower leaves. Physiol. Plant. 91:334-338.

McMurtrey, J. E., Chappelle, E. W., Kim, M. S., Meisinger, J. J., and Corp, L. A. (1994), Distinguishing nitrogen fertilization levels in field corn (Zea mays L.) with actively induced fluorescence and passive reflectance measurements. Remote Sens. Environ. 47:36-44.

Milton, N. M., Ager, C. M., Eiswerth, B. A., and Power, M. S. (1989), Arsenic- and selenium-induced changes in spectral reflectance and morphology of soybean plants. Remote Sens. Environ. 30:263-269.

Milton, N. M., Eiswerth, B. A., and Ager, C. M. (1991), Effect of phosphorus deficiency on spectral reflectance and morphology of soybean plants. Remote Sens. Environ. 36: 121-127.

Moran, R. (1982), Formulae for determination of chlorophyllous pigments extracted with $\mathrm{N}, \mathrm{N}$-Dimethylformamide. Plant Physiol. 69:1376-1381.

Nenova, V., and Stoyanov, I. (1993), Physiological and biochemical changes in young maize plants under iron deficiency I. Growth and photosynthesis. J. Plant Nutr. 16: 835-849.

Oertli, J. J., and Jacobson, L. (1960), Some quantitative considerations in iron nutrition of higher plants. Plant Physiol. 35:683-688.

Ohki, K. (1984), Manganese deficiency and toxicity effects on growth, development, and nutrient composition in wheat. Agron. J. 76:213-218.

Römheld, V., and Marschner, H. (1986), Rhythmic iron stress reactions in sunflower and suboptimal iron supply. Physiol. Plant. 53:347-353.

Savitzky, A., and Golay, M. J. E. (1964), Smoothing and differentiation of data by simplified least square procedures. Anal. Chem. 35:1627-1639.

Schneiter, A. A., and Miller, J. F. (1981), Description of sunflower growth stages. Crop Sci. 21:901-903.

Steel, R. G. D., and Torrie, J. H. (1981), Principles and Procedure of Statistics, McGraw-Hill, New York. 